\title{
Fenomenologia de arquitetura. Discursos de Christian Norberg-Schulz e Juhani Pallasmaa
}

\author{
Ricardo Chaves Hernández
}

Artículo

Afiliación: Universidad de Costa Rica, San José, Costa Rica

E-mail: ricardo.chaves@ucr.ac.cr

Recibido: 4 de marzo del 2019

Aceptado: 12 de abril del 2019

\section{Ricardo Chaves Hernández}

Licenciado en Arquitectura por la Universidad de Costa Rica y Maestro en Creación Artística Contemporánea por la Universidade de Aveiro, Portugal. Actualmente es docente e investigador de la Universidad de Costa Rica. Indaga sobre las relaciones entre arte y arquitectura contemporánea.

\begin{abstract}
Resumo
$\mathrm{Na}$ teoria arquitetónica, a fenomenologia entende-se como um movimento que investiga a arquitetura enquanto experiência humana. Dentro desse movimento, este artigo destaca dois discursos: o de Christian Norberg-Schulz e de Juhani Pallasmaa por apresentarem, respetivamente, uma "fenomenologia do exterior" e uma "fenomenologia do interior"- domínios pertencentes e interdependentes da arquitetura. Estes arquitetos-fenomenólogos problematizaram sobre arquitetura-lugar e arquitetura-corpo para marcar as suas posições críticas ao movimento moderno e pós-moderno. 0 objetivo deste artigo é compreender e confrontar esses discursos por representarem uma sequencialidade de pensamentos que (conclui-se) "abrem a porta" a uma (nova) fenomenologia contemporânea na arquitetura. O desenvolvimento do tema passa pela abordagem das problemáticas da arquitetura enquanto imagem e arquitetura de presença corporal; esta última essencial para a fenomenologia contemporânea. Metodologicamente, apresenta-se esse seguimento lógico seguido de uma contraposição das ideias abordadas. Conclui-se, destacando os pensamentos de Norberg-Schulz e Pallasmaa que desenvolvem a análise da noção do corpo na fenomenologia de arquitetura. Esta ampliação encaminha e introduz a fenomenologia contemporânea (fenomenologia de atmosfera como qualidade arquitetónica), aplicação efetiva na prática atual para arquitetos proeminentes como Daniel Libeskind, Steven Holl e Peter Zumthor.
\end{abstract}

Palavras chave: arquitetura; Christian Norberg-Schulz; corpo; exterior-interior; fenomenologia; Juhani Pallasmaa.

\section{Phenomenology of architecture. Discourses of Christian Norberg-} Schulz and Juhani Pallasmaa

\begin{abstract}
In architectural theory, phenomenology is understood as a movement that investigates architecture as a human experience. Within this movement, this article highlights two discourses: that of Christian Norberg-Schulz and Juhani Pallasmaa for presenting, respectively, a "phenomenology of the exterior" and a "phenomenology of the interior"architectural domains that are interdependent. These architects-phenomenologists have argued about architecture-place and architecture-body in order to state out their critical viewpoint towards the modern and postmodern movement. The purpose of this article is to understand and confront these discourses by representing a sequentiality of thoughts that (in conclusion) "open the door" to a (new) contemporary phenomenology in architecture. The development of the theme involves the approach of the problems of architecture as an image and architecture of body presence, the latter essential for contemporary phenomenology. Methodologically, this logical follow-up is presented and followed by a contrast of the ideas addressed. It ends with the highlighting of the thoughts of Norberg-Schulz and Pallasmaa that developed the analysis of the notion of the body in the phenomenology of architecture. This expansion promotes and introduces contemporary phenomenology (atmospheric phenomenology as architectural quality) as an effective application in current practice for prominent architects such as Daniel Libeskind, Steven Holl, and Peter Zumthor.
\end{abstract}

Keywords: architecture; Christian Norberg-Schulz; body; exterior-interior; phenomenology; Juhani Pallasmaa. 


\section{Resumen}

En la teoría arquitetónica, la fenomenología se entiende como un movimiento que investiga la arquitectura como experiencia humana. Dentro de ese movimiento, este artículo destaca dos discursos: el de Christian Norberg-Schulz y el de Juhani Pallasmaa por presentar, respetivamente, una "fenomenología del exterior" y una "fenomenología del interior"- dominios pertenecientes y interdependientes de la arquitectura. Estos arquitectos-fenomenólogos problematizaron sobre arquitectura-lugar y arquitecturacuerpo para señalar sus posiciones críticas al movimiento moderno y pos-moderno. O objetivo de este artículo es interpretar y confrontar esos discursos por representar una secuencialidad de pensamientos que (se concluye) "abren la puerta" a una (nova) fenomenología contemporánea en la arquitectura. El desenvolvimiento del tema pasa por el abordaje de las problemáticas de la arquitectura como imagen y arquitectura de presencia corporal; esta última esencial para la fenomenología contemporánea. Metodológicamente, se presenta ese seguimiento lógico seguido de una contraposición de las ideas abordadas. Se concluye, destacando los pensamientos de Norberg-Schulz y Pallasmaa que amplían el análisis de la noción del cuerpo en la fenomenología de arquitectura. Esta ampliación encamina y introduce la fenomenología contemporánea (fenomenología de atmósfera como cualidad arquitetónica), aplicación efectiva en la práctica actual para arquitectos prominentes como Daniel Libeskind, Steven Holl y Peter Zumthor.

Palabras chave: arquitectura; Christian Norberg-Schulz; cuerpo; exterior-interior; fenomenología; Juhani Pallasmaa. 


\section{Introdução}

presente artigo tem como objetivo expor e analisar dois discursos sobre fenomenologia na arquitetura: os de Christian Norberg-Schulz e Juhani Pallasmaa. A escolha destes pensadores entende-se como valiosa por apresentarem discursos que, embora antagónicos, se tornam complementares. Ao compreender os seus pensamentos percebe-se a importância das suas ideias enquanto embrionárias para uma sequencialidade de concepções a uma (nova) fenomenologia contemporânea na arquitetura. No estudo realizado percebe-se que as suas visões, apesar de surgirem em tempo (épocas) e espaço diferentes e apresentarem ausências teóricas, são pensamentos que reunidos potenciam-se. Este artigo pretende evidenciar essa relação de posições por entender que a mesma representa uma ponte à fenomenologia de arquitetura abordada e praticada na atualidade.

Metodologicamente, os discursos são analisados isoladamente segundo uma ordem espaço temporal em que foram expostos pelos autores no sentido de compreendê-los no seu contexto (e num contexto atual). Segundo esta sequência é possivel evidenciar enquanto contrapostos e estabelecer a complementaridade sobre a qual se constrói um novo discurso.

Pelo alcance e contributo deste artigo, e para a compressão do mesmo, é importante perceber a distinção entre: fenomenologia na arquitetura (de Christian Norberg-Schulz, Kenneth Frampton, Juhani Pallasmaa e Steven Holl) e fenomenologia na filosofia (de Edmund Husserl, Martin Heidegger e Maurice Merleau-Ponty). Embora a fenomenologia na arquitetura seja influenciada pela fenomenologia filosófica (os expoentes da fenomenologia na arquitetura fundamentam-se na fenomenologia na filosofia) não são análogas e têm destinos distintos. No que respeita à relação existente entre as fenomenologias (filosófica e arquitetónica), este artigo interessa-se, fundamentalmente, no que as influências acima referidas originaram e refletiram nos pensamentos dos arquitetos selecionados.

Para compreender o propósito deste artigo deve-se entender que há fenomenologias e há fenomenólogos e portanto, a fenomenologia compreende-se de diferentes formas: como "um retorno às coisas mesmas" (Husserl), como um "método" ou "forma de ver" (Heidegger), ou como "a essência da perceção" (Merleau-Ponty). Estas conceções filosóficas têm sido aplicadas e adotadas por arquitetos fenomenólogos na teoria e na prática. A forma como os arquitetos fenomenólogos compreendem a fenomenologia está influenciada pelos filósofos que tomam como referência. Norberg-Schulz compreende (como Heidegger) a fenomenologia como um método: "para penetrar no mundo de cada existência" (Norberg-Schulz em Shirazi, 2014, p. 3). Por a sua vez, Pallasmaa usa o conceito de Husserl para se referir à fenomenologia como um "olhar puro" do fenómeno ou "ver a sua essência" (Pallasmaa, 1996, p. 450). Steven Holl refere-se à fenomenologia como o estúdio das essências; para Holl arquitetura tem o potencial de "pôr essências de volta à existência" (Holl, 1996, p. 11). Todas estas interpretações de fenomenologia como uma "maneira" ou "método" ou até mesmo "abordagem", evidenciam a confiança que os arquitetos depositam nela para a observação e estudo de temas arquitetónicos. Pensar e ver a arquitetura fenomenologicamente permitiu-lhes aprofundar mais os problemas da arquitetura e na essência dos mesmos. A cristalização da fenomenologia pela prática (arquitetónica) a encontramos nas questões colocadas por arquitetos proeminentes estudiosos no tema como Daniel Libeskind, Steven Holl e

$1 \quad$ Em termos gerais fenomenologia é uma teoria dos fenómenos ou do que aparece. Etimologicamente a palavra reúne os termos

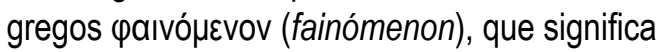
fenómeno, o que manifesta-se, o que mostra-se,

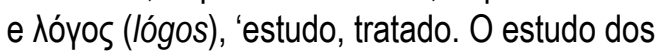
fenómenos, da forma em como são percebidos na consciência do individuo para compreender 0 mundo, influenciou os discursos da fenomenologia na arquitetura.
Peter Zumthor, nas descobertas e revelações, e através da referência das suas obras.

Este artigo compõe-se por quatro partes: a primeira etapa numa breve contextualização temporal da fenomenologia na arquitetura para dar sequência numa segunda parte ao desenvolvimento dos discursos dos arquitetos fenomenólogos Norberg-Schulz e Juhani Pallasmaa; na terceira parte pretende-se confrontar os discursos analisados reconhecendo neles a sua complementaridade para facilitar a leitura a uma fenomenologia atual. 0 artigo finaliza com as conclusões. 


\section{Contexto geral}

$\mathrm{Na}$ arquitetura a fenomenologia manifesta-se enquanto movimento filosófico nos anos 50s. Surgiu como uma investigação teórica da arquitetura como (esta aparece na) experiência humana. Na década dos 70 s inicia o seu apogeu (vigente até hoje). No auge pós-moderno da fenomenologia estabeleceram-se certas posições críticas às conceções da prática arquitetónica moderna e pós-moderna da altura. Numa primeira fase de abordagem, os principais exponentes foram: Christian Norberg-Schulz, que criticou as medidas adotadas na concepção da cidade moderna e o estilo internacional e, no início dos anos 80s, Kenneth Frampton, ao criticar a "indiferença" com o lugar e a "atenção à forma" na arquitetura moderna. Frampton numa fenomenologia latitudinal consciencializou sobre a hapticidade na experiência arquitetónica como forma de reencontro com lugar; esta conscientização criou uma ponte a uma segunda abordagem fenomenológica arquitetónica cujos principias exponentes são Steven Holl, Juhani Pallasmaa e Alberto Pérez-Gómez. Eles expuseram, respetivamente, uma fenomenologia em prática, uma fenomenologia frágil e uma fenomenologia enquanto meio para redescobrir a primazia da perceção.

Como foi anteriormente referido, os discursos dos arquitetos fenomenólogos foram influenciados pelos pensamentos dos filósofos Edmund Husserl, Martin Heidegger, Maurice Merleau-Ponty e também Gastón Bachelard. Neste artigo, pelos alcances que tem, são analisadas as contribuições de Christian Norberg-Schulz e de Juhani Pallasmaa correspondes à primeira e segunda fase da cronologia da fenomenologia na arquitetura.

\section{Uma fenomenologia do exterior A fenomenologia por parte de Christian Norberg-Schulz}

$\mathrm{O}$ arquiteto norueguês, teórico e historiador da arquitetura Christian Norberg-Schulz, abordou a problemática arquitetura-lugar, influenciado por Heidegger, enquanto meio para compreender a arquitetura à luz da traço existencial no mundo. Nomeou o termo "Genius loci" para designar um conceito que identifica a particularidade de um lugar na procura de revelar o que é ou quer ser através da arquitetura. Para Norberg-Schulz, a arquitetura significa visualizar o genius loci, isto através da criação, por parte dos arquitetos, de "lugares significativos" (espaços com carácter distintivo) que "ajudem o homem a habitar" (Norberg-Schulz, 1980, p. 5).

No encontro fenomenológico do genius loci há um reconhecimento e reunião dos significados, potencialmente presentes do lugar, para uma interpretação numa linguagem arquitetónica ${ }^{2}$ que tem como objetivo preservar "o espírito" desse lugar. A aproximação aos lugares, o seu contexto nas suas relações com as outras coisas concretas, para o reconhecimento de algo como algo, dum espaço como espaço, vem a ser o fim do genius loci. A interpretação que esta linguagem provoca manifesta-se através dum processo que "reúne o mundo numa paisagem habitada" (reúnem-se entidades naturais e feitas pelo homem). Esta é-nos aproximada pelos "edifícios" que, ao reunir as propriedades da mesma numa linguagem arquitetónica, fazem (metafóricamente) a paisagem "falar" tal como explicou Norberg-Schulz (em Norberg-Schulz, 1979); concluindo que pela tradução arquitetónica é possível que as obras sejam "objetos de identificação humana" pelo que "encarnam significados existênciais e fazem que o mundo destaque tal como é" (Norberg-Schulz em Shirazi, 2014, p. 50).

$2 \quad$ A linguagem arquitetónica tem a capacidade de traduzir a realidade vivida numa segundo Norberg-Schulz, por três componentes estruturais básicos interrelacionados, a saber: topologia, morfologia e tipologia. Na arquitetura a topologia concerne à organização espacial duma obra, a morfologia é relativa a como as formas na arquitetura são articuladas para definir uma espacialidade concreta e tipologia refere-se ao tipo de espaço que reúne modos ou manifestações de existir (Norberg-Schulz, 1979).
A teoria do lugar de Norberg-Schulz compreende-se num contexto de contraposição às medidas que pretendiam criar lugares novos que marcassem a transição da cidade industrial do século XIX à cidade moderna, nomeadamente, a aplicação - a nível urbano do plano "aberto" da morada moderna, entendido como um continuum "fluido" caracterizado pela ausência de distinção entre o interior e exterior; e a implantação do "estilo internacional" que, pelo descuido dos caracteres locais e regionais a favor de princípios válidos de as todas partes, produz "um entorno aberto e monótono incapaz de união" (Shirazi, 2014, p. 54). Estas medidas, segundo explica Norberg-Schulz, 
originaram os chamados "não lugares"; os quais caracterizam-se por serem espaços "matemático-tecnológicos", denunciando que são nestas abstrações que se situam a maioria dos edifícios modernos (Norberg-Schulz, 1980).

As medidas arquitetónicas implementadas para a mudança à modernidade, conforme aborda Norberg-Schulz, resultaram numa perda de identidade e carácter dos lugares, suscitando à consciência a necessidade de "significado na arquitetura", necessidade esta que foi traduzida numa "nova monumentalidade" e "novo regionalismo". A primeira refere-se à "memória e símbolos que servem para enraizar de maneira geral à humanidade no tempo", e a segunda faz referência ao enraizamento no lugar ${ }^{3}$ (NorbergSchulz em Shirazi, 2014, p. 55). Este último exige uma abordagem fenomenológica porque ocupa-se do que está próximo e está vinculado o "ser-no-mundo"4 como explica Norberg-Schulz (em Shirazi, 2014).

Na sua obra Genius Loci: Towards a Phenomenology of Architecture (1980) NorbergSchulz faz uma interpretação fenomenológica onde o conceito genius loci vem a ser essência central da (sua) compreensão sobre arquitetura e fundamento da (sua) teoria do lugar. A teoria de Norberg-Schulz sustenta-se numa seleção de exemplos arquitetónicos enunciados nos documentos escritos do filósofo Heidegger, tais como: "o Templo grego" em The Origin of the Work of Art (1936), "a ponte" e "a casa de campo" em Building Dwelling Thinking (1951) e no poema de Georg Trakl "Noite de Inverno" em Language (1950). Segundo M. Reza Shirazi em Towards an Articulated Phenomenological Interpretation of Architecture: Phenomenal Phenomenology (2014), estes exemplos analisados por Norberg-Schulz, centralizam-se unicamente em aspetos que observam a arquitetura desde o exterior, o que leva a uma interpretação parcializada à exterioridade e aparência externa dos casos limitando, consequentemente, o (seu) genius loci como método fenomenológico para uma interpretação completa (e articulada) da arquitetura (pp. 56-58). Shirazi explica que, embora Norberg-Schulz seja essencialmente Heideggereano e coloque os seus exemplos como fonte de inspiração, a análise que (Norberg-Schulz) faz gera um entendimento errado sobre Heidegger pois este filósofo considera a arquitetura como um todo integrador do espaço exteriorinterior. Este raciocínio de Shirazi, de certa forma, desafia a ideia de genius loci de Norberg-Schulz e consequentemente o entendimento deste sobre fenomenologia. Nas palavras de Shirazi:

Um pode argumentar que a fenomenologia de Norberg-Schulz e o genius loci apresentam um tipo de "fenomenologia de fora". Ela raramente toca a porta e entra no interior. "Genius loci" passeia pelos arredores, olha para os edifícios desde o exterior, sobrevoa o entorno, e as vezes aproxima-se aos edifícios, mas mantem-se fora da entrada. "Genius loci" é principalmente aéreo. Para usar um termo fílmico: dá "tiros longos", não primeiros planos. Entende a arquitetura desde cima, e rara vez situa-se na terra. (Shirazi, 2014, p. 58)

Na leitura feita por Shirazi conclui-se que a fenomenologia de Norberg-Schulz, que toma como ponto de partida o conceito de genius loci, está centrada na "relação do estabelecimento com o entorno e a forma como o reúne" (Shirazi, 2014, p. 61). Existe um reducionismo do conceito a uma encenação arquitetónica adaptada em termos figurativos (formais) ao (carácter dado e configuração do) lugar. Da etimologia do conceito genius loci enquanto "espírito (protetor) dum lugar" conclui-se também que este é intrinsecamente "macro" (de implicações de ordem macro) (Shirazi, 2014).

3 Norberg-Schulz coloca como exemplo de regionalismo à obra Villa Mairea de Alvar Alto já que segundo indica o genius loci finlandês está fortemente presente na obra; até o ponto de sintetizar o seu lugar específico (Norberg-Schulz, 1980).

$4 \quad$ "Ser no mundo" é um neologismo da terminologia Heideggereana que refere-se às atitudes do homem em relação ao mundo. Consiste em uma compreensão intuitiva do mundo e previamente uma noção do que existe no seu interior para conseguir habitá-lo (Amorim, 2013, p. 11). Heidegger adverte que: "só se formos capazes de habitar ("sermos no mundo") poderemos construir" (arquitetura) (Heidegger, 1993, p. 362).
Com a finalidade de exemplificar o genius loci como conceito aplicado ao lugar, Norberg-Schulz em Genius Loci: Towards a Phenomenology of Architecture (1980) fez uma análise estética das cidades de Praga, Cartum e Roma. Essa analise, possuída pelo alemão historiador e teórico de arquitetura Eduard Führ, foi fundamental para dirigir dois argumentos críticos ao conceito apresentados em: 'Genius loci' Phänomen oder Phantom? (1998). O primeiro argumento questiona a forma como Norberg-Schulz ilustra o "espírito do lugar" através das imagens das cidades que expõe. Führ, para quem fenomenologia da arquitetura significa "compreender, ler e produzir arquitetura como parte do nosso mundo da vida" (Shirazi, 2014, p. 62), afirma que o genius loci de Norberg-Schulz "é um fenómeno fotográfico e não arquitetónico", que obedece a uma produção de um olhar fotográfico (o qual é suposto ser de Norberg-Schulz). As imagens específicas das cidades estão delimitadas por uma estética de pontos de vistas seletivos e fixos, pelos enquadramentos, e pela óptica utilizada. Por tanto uma 
produção fotográfica com um olhar diferente evidenciaria um entendimento diferente do conceito. No segundo argumento de Führ, revela que o genius loci baseia-se, fundamentalmente, na ausência de pessoas e suas atividades predeterminando uma visão desprovista de vida nesse sentido, o qual explica da seguinte forma:

O "genius loci" é para Norberg-Schulz um "fenómeno" que parece emergir mais na ausência de pessoas do que pela sua presença ou mesmo suas atividades na paisagem. $O$ "genius loci" não é a qualidade ou propriedade dum mundo de vida, se não uma objetividade experimentada. (Shirazi, 2014, p. 62)

Nesta sequência Reza Shirazi expõe mais um argumento crítico ao conceito aplicado ao lugar genius loci de Norberg-Schulz: Shirazi explica que nas interpretações de Norberg-Schulz, segundo o que exemplifica, tanto a nível urbano como de escala do edifício, o corpo do sujeito permanece estático. Na teoría de Norberg-Schulz parece que há um esquecimento ou ausência do papel do movimento na perceção do espaço. O genius loci centraliza-se numa concretização e numa "encarnação" no sítio, mas esta encarnação de Norberg-Schulz, refere-se apenas ao corpo do edifício e não o corpo de quem esta presente, que aparenta ser "omnipresente". O corpo no genius loci está em pontos especiais e não se movimenta pelo espaço, o sujeito fixa-se num ponto onde o genius loci the é revelado sem se movimentar dessa posição. Esta experiência unidimensional da obra arquitetónica "restringe o genius loci e o faz imóvel" (Shirazi, 2014, p. 63).

Segundo Shirazi o conceito de genius loci, no entendimento de Norberg-Schulz, é determinado por uma "fenomenologia externa", esta torna-se insuficiente para uma interpretação fenomenológica da arquitetura como um todo (interior e exterior). Shirazi reclama que o genius loci tem a potencialidade de interpretar a arquitetura num sentido completo, que considera necessário para o entendimento da fenomenologia da arquitectura (Shirazi, 2014). Conclui-se que o genius loci determinado por uma "fenomenologia externa" representa um descuido teórico por parte de Norberg-Schulz.

\section{Uma fenomenologia do interior A fenomenologia por parte de Juhani Pallasmaa}

O arquiteto e fenomenólogo finlandês Juhani Pallasmaa começa a construção do seu discurso fenomenológico a partir de uma crítica à hegemonia da visão (o predomínio da vista sobre o resto de sentidos) como condição distintiva na formação de conhecimento na cultura ocidental. Tal preeminência, que desde os gregos manifesta-se na analogia entre conhecimento e a visão clara e na metáfora da luz como verdade, viu-se evidenciada com a descoberta da representação da perspectiva; sobretudo por esta surgir como "instrumento de pensamento arquitetónico" já que, ao estar baseada precisamente no olho do observador, condiciona a perceção. Nas palavras de Pallasmaa:

A invenção da representação em perspectiva fez do olho o ponto central do mundo percetivo, assim como o conceito do eu. A própria representação em perspectiva converteu-se numa forma simbólica que não só descreve se não que também condiciona a perceção. (Pallasmaa, 2006, p. 15)

Nos seus argumentos críticos sobre o paradigma ocular-central, Pallasmaa destaca algumas observâncias por parte dos filósofos Descartes, Merleau-Ponty e Heidegger, orientadas, respetivamente, à identificação e reconhecendo do tato enquanto sentido "mais certeiro e menos vulnerável ao erro", a denunciar "o olho cartesiano do espectador externo desencarnado do mundo", e a hegemonia da visão na era moderna que pretende, erroneamente, a "conquista do mundo como uma imagem" (Pallasmaa, 2006, p. 20).

$\mathrm{Na}$ (teoria da) arquitetura ocidental a elaboração do sistema arquitetónico de ordens (dórico, jónico e coríntio) por parte dos gregos marcaram o início da concepção da arquitetura como uma arte retinal. Na era moderna, o famoso credo de Le Corbusier: "a arquitetura é o jogo sábio, correto e magnífico dos volumes reunidos na luz", e o planeamento urbano moderno baseado no olho cartesiano vista de cima (para um controlo da totalidade) sustentaram ${ }^{5}$ a concepção da arquitetura como uma arte 
retinal até os nossos dias (Pallasmaa, 2006). Pallasmaa observa como tem surgido um detrimento na arquitetura pela sua conversão na produção de imagem (fotográfica) e como tal, os edifícios são produto de uma perca de tactilidade, das proporções e pormenores arquitetados para o corpo humano neles. Portanto, perdem o sentido da "aura", termo do qual se apodera de Walter Benjamin para referir "a autoridade da presença, uma qualidade necessária para uma obra autêntica" (Pallasmaa, 2006, pp. 29-30). Num sentido de contradizer tais observações, e com a finalidade de alcançar uma experiência plástica e espacial com base existencial na arquitetura, Pallasmaa propõe a noção de "arquitetura multissensorial" enquanto ideia que vai ao encontro da presença de todos os sentidos na perceção do espaço arquitetónico. Esta ideia confere-Ihe um carácter especial à sua fenomenologia, que explica da seguinte forma:

A experiência da arquitetura é multissensorial; as qualidades do espaço, da matéria, e da escala medem-se a partes iguais pelo olho, o ouvido, a nariz, a pele, a língua, 0 esqueleto e o músculo". A arquitetura fortalece... a sensação de estar no mundo, dando lugar essencialmente a uma experiência fortalecida do eu. (Pallasmaa, 2006, p. 43)

Numa experiência arquitetónica multissensorial, a sensibilidade háptica assume um papel fundamental pois o sentido do tato interage com outros sentidos na perceção do espaço. O despertar da sensibilidade háptica está apoiada e inspirada em figuras de pensamento da filosofia sensorial de Merleau-Ponty que compreendem a visão associada ao sentido do tato (como é citada em Pallasmaa, 2006): "vemos a profundidade, o aveludado, a suavidade, a dureza dos objetos..." (relativa à dimensão material) e, por parte do historiador Martin Jay, o verso (poético e relativo ao reino espiritual) "através da vista tocamos o sol e as estrelas" (Pallasmaa, 2006, p. 44).

Pallasmaa apela à ação de carácter sinestésico de "tocar com os olhos" onde o olhar implica "um toque inconsciente, uma mimeses e uma identificação corporal" (Pallasmaa, 2006, p. 43) para fazermos compreender o que é para ele o propósito da arquitetura: "arquitetura elabora e comunica ideias do confronto encarnado do homem com o mundo através de "emoções plásticas" (Pallasmaa, 2006, p. 47). Na minha opinião (Pallasmaa parafraseando a Merleau-Ponty): "a tarefa da arquitetura é tornar visível como nos toca o mundo" (Pallasmaa, 2006, p. 47). Nas suas observações críticas ao paradigma ocular-central o olho é qualificado como o órgão da distancia e da separação; que inspeciona, controla e investiga, enquanto que o tato o da proximidade, da intimidade e 0 afeto; que acerca-se e acaricia (Pallasmaa, 2006).

Pallasmaa reconhece nas experiências emocionais plásticas (pictóricas e arquitetónicas) o valor das sombras e da luz ténue como ativadoras da imaginação; estas - segundo explica - significam (para o observador sensível) "um olhar com a mente ausente". Nas sombras e na escuridão dos espaços interiores onde a janela mantém o seu significado ontológico pensa-se mais profundamente. Coloca como exemplo arquitetónico a câmara municipal de Säynätsalo em Finlândia, da autoria do arquiteto Alvar Alto, na qual, e em suas palavras: "a escuridão enriquece o poder da palavra e cria um sentido de comunidade místico e mitológico" (Pallasmaa, 2006, p. 50).

Complementar à experiência visual da penumbra, o ouvir sons característicos dos aposentos, estrutura e articula a experiência e a compreensão dos mesmos. Pallasmaa explica que o som, normalmente, provê o "continuum 6 temporal" no qual se incorporam as impressões visuais, e o espaço que traça o ouvido na escuridão, acaba por se tornar numa "cavidade esculpida diretamente no interior da mente" (Pallasmaa, 2006, pp. 50-51). 0 som mede o interior e faz com que a sua escala seja compreensível para nós; mas adverte, neste sentido que, se o volume acústico do som é reduzido ou neutralizado, cegamos os nossos ouvidos, pois é com os quais que "acariciamos os

$5 \quad$ A propagação de imagens publicitárias nos meios escritos e audiovisuais, valorizaram a capacidade de mostrar ou ser mostrado $e$ reforçaram o referido paradigma da visão.

6 Continuum faz alusão ao sentido de continuidade espaço-temporal no que sustentam os atos da vida. Numa cena fílmica, por exemplo, a vida é apoiada num continuum, sem o qual a mesma perde a sua força. limites do espaço" (Pallasmaa, 2006, p. 52).

A tranquilidade é uma experiência auditiva primordial criada pela arquitetura. Experimenta-se através do silêncio e da solidão num diálogo privado entre a obra e a pessoa sensível. Para Pallasmaa uma arquitetura do silêncio que aponta a uma espontaneidade e autenticidade da experiência individual é ascética, concentrada e contemplativa e qualifica-a como uma "arte do silêncio petrificado". Uma experiência arquitetónica poderosa silencia todo o ruído exterior, centra a (nossa) atenção sobre (nossa) própria experiência e (como acontece na arte) faz-nos ser conscientes de nossa solidão fundamental (Pallasmaa, 2006). Neste aspeto Pallasmaa faz ver como 
a experiência da tranquilidade experimentada num tempo desacelerado não coincide com a realidade do último século, onde segundo afirma "a perca (compressão) da duração do tempo e do seu eco histórico ameaça o sentido do eu como um ser histórico" (Pallasmaa, 2006, p. 54).

Pallasmaa destaca a relação entre o sentido do olfato com a memória espacial na autêntica experiência arquitetónica. Afirma que frequentemente a recordação mais persistente de qualquer espaço é o seu aroma: "Um cheiro particular guardado na memória faz-nos entrar sem tomar conta num espaço completamente esquecido pela memória retiniana; as narinas acordam uma imagem esquecida e caímos num vivido devaneio" (Pallasmaa, 2006, p. 55). O valor do imaginário olfativo das palavras também destaca-se em poemas, como os de Rainer Maria Rilke, por terem um poder emocional e associativo que - continua denunciando Pallasmaa- contrasta com 0 imaginário generalizado da arquitetura atual (Pallasmaa, 2006).

Na experiência arquitetónica multissensorial, destaca-se também, o papel do sentido do tato e a relação que este tem com o gosto na perceção do espaço: "a pele lê a textura, o peso, a densidade e a temperatura da matéria" (Pallasmaa, 2006, p. 58). Com a pele nua consegue-se sentir e perceber o espaço, a sua materialidade e 0 que ela expele (transfere). Explica-se que existe uma subtil transferência entre as experiências tácteis e a degustação. A língua sente subliminarmente a superfície duma pedra delicadamente polida e reconhece uma superfície deliciosamente coloreada. Por exemplo as cores sensuais dos muros das casas de Luís Barragán com frequência evocam experiências orais. Para Pallasmaa "a origem mais arcaica do espaço arquitetónico está na cavidade bucal" (Pallasmaa, 2006, p. 60); reconhece que o corpo sabe e recorda e que o significado arquitetónico deriva da (força de) memória corporal, é dizer da experimentação primitiva dos espaços transmitida de geração em geração e que conforma as nossas sensações de conforto, proteção e lar (Pallasmaa, 2006).

Pallasmaa tece críticas aos arquitetos de arquitetura moderna, nomeadamente ao reconhecimento da arquitetura apenas pela experiência visual (no que diz respeito ao exterior) bem como na redução do carácter da arquitetura a um instrumento de funcionalidade simples, de conforto corporal e/o de prazer sensorial que perde a sua prática existencialmente mediadora. Declara: "uma peça de arquitetura não deveria tornar-se transparente nas suas intensões utilitárias e racionais; tem que manter o seu secreto e mistério impenetráveis com o fim de prender a nossa imaginação e as nossa emoções" (Pallasmaa, 2006, p. 63).

Citando o filósofo Henri Bergson, Pallasmaa refere-se à ação que, de alguma maneira, refletem os objetos que rodeiam o corpo e que na arquitetura, esta suposta ação faz 0 corpo reagir, tornando esta experiencia indissociável da arquitetura. Sobre esta base percetiva Pallasmaa expõe a sua ideia duma arquitetura de verbos diante de uma de substantivos (Pallasmaa, 2006). Explica que uma experiência arquitetónica significativa não consiste numa coleção de imagens retinianas mas pelo contrário, consiste numa experiencia mais abrangente, ao aproximar-se, e ao entrar num edifico e olhar pelas aberturas em vez de ficar com uma imagem retinal isolada da fachada, da entrada ou da janela respetivamente exemplificada (Pallasmaa, 2006). A tridimensionalidade da arquitetura experimenta-se através do corpo, movimento e ação, fazendo da experiencia uma outra, que é em essência verbal. O espaço arquitetónico é um espaço vivido que transcende o seu próprio físico e deve ser entendido em termos das interações e inter-relações dinâmicas que produz. Neste sentido Pallasmaa refere o professor Fred Thompson para descrever a experiência arquitetónica com infinitivos e não com substantivos; tornando as noções de espaço e tempo em "espacear" e "temporizar" na devida ordem (Pallasmaa, 2006, p. 66).

Nesta resultante de ideias Pallasmaa reconhece também o carácter situacional da arquitetura ao identificar a relação da "imagem do eu com o espaço onde estou" (sitio-lugar) (Pallasmaa, 2006, p. 66). Segundo explica, as nossas ações humanas de orientação, posicionamento e reconhecimento (fenomenológico) do espaço estão enraizadas no nosso inconsciente coletivo. A perceção, a memória e a imaginação estão em constante interação:

Nas experiências memoráveis de arquitetura, o espaço, a matéria e o tempo fundem-se numa única dimensão, na sustância básica do ser que penetra na nossa consciência. Nos 
identificamos com este espaço, este lugar, este momento, e estas dimensões passam a ser ingredientes da nossa mesma existência. A arquitetura é a arte da reconciliação entre nós e o mundo, e esta mediação tem lugar através dos sentidos. (Pallasmaa, 2006, p. 72)

Para Pallasmaa, o papel da arquitetura é a criação de espaços com carácter existencial de forma a estruturarem o nosso ser-no-mundo. Afirma que a arquitetura materializa, estrutura e faz compreender quem somos (Pallasmaa, 2006). Assim, Pallasmaa adverte que só a verdadeira arquitetura pode cumprir as condições básicas, os sentimentos emocionais e os aspetos existenciais dos seres humanos; o restante é mera construção.

Aconsideração do "corpo como centro do mundo experiencial" por parte de Merleau Ponty influenciou Pallasmaa para este considerar o corpo como integrador das experiências sensoriais. Percepções específicas e por vezes inconscientes da arquitetura, como a "medição" corporal da escala do edifício, implica que há uma projeção do esquema do próprio corpo no espaço. Ao experimentar um edifício, inconscientemente, imitamos a sua configuração estrutural nos nossos ossos e músculos e dessa forma chegamos a uma compreensão do mesmo, e quando o corpo descobre a sua ressonância no espaço, sentimos prazer e proteção (Pallasmaa, 2006). Nesta relação corporal com o espaço e a gravidade como sentido consciencializamo-nos da nossa relação com a arquitetura. Nas palavras de Pallasmaa:

O sentido da gravidade é a essência de todas as estruturas arquitetónicas e a grande arquitetura faz-nos ser conscientes da gravidade e da terra. A arquitetura fortalece a experiência da direção vertical do mundo. Ao mesmo tempo, faz-nos ser conscientes da profundidade da terra, faz-nos sonhar com a levitação e o voo. (Pallasmaa, 2006, p. 68)

Assim como arquitetura fortalece a experiência da direção vertical do mundo, também propicia a experiência da direção horizontal pelos percursos que configuram, dirigem e adequam a atitude e o movimento do sujeito no espaço. Essa possibilidade da ação faz da autêntica experiência arquitetónica uma outra que é manifesta em essência verbal. Aqui o verbo como experiencia motriz da arquitetura contrapõe-se à experiência tipo substantivo que é, por definição, imóvel e constante (Pallasmaa em Shirazi, 2014).

Pallasmaa acredita que na experiência arquitetónica existencial, o sujeito perceptor encontra-se com o espaço percebido. Há um diálogo, uma espécie de intercâmbio e uma permutação em que o corpo funde-se com o espaço para criar um (chamado) "espaço corporal". Descreve-o assim: "localizo-me num espaço e o espaço instala-se em mim" (Pallasmaa em Shirazi, 2014, p. 73). O corpo agrega, num envolvimento na arquitetura, dirige, escala e enquadra ações, percepções e pensamentos nas ações de entrar, abordar e confrontar a um edifício (Pallasmaa em Shirazi, 2014).

Aanteriormente referida - noção de "arquitetura multissensorial" - pode-se traduzir numa arquitetura dos sentidos que apela ao encontro do corpo com as coisas ao seu ao redor, constitui aqui o ponto mais proeminente do discurso fenomenológico de Pallasmaa. 0 segundo ponto o constitui a experiência verbal da arquitetura. A experiência verbal, em contraposição a uma nominal, "provoca um compromisso multidimensional e multissensorial com o entorno, devido ao facto de que um corpo em movimento é mais aberto e preparado que um corpo estático" (Shirazi, 2009, p. 82). Para enfrentar o aspeto dominante e problemático na história da perceção da supremacia da visão na arquitetura ocidental, Pallasmaa alerta à presença e inter-relação de todos sentidos na perceção e experimentação da arquitetura. Neste processo, a sensibilidade háptica cria uma experiência de proximidade com coisas que apelam ao interesse corpóreo e íntimo da arquitetura", ação que nos leva ao interior do edifício. A experiência multissensorial sugere uma "visão periférica" que é oposta a uma "focada". A "visão periférica" transforma as imagens retinais em experiências espaciais e corporais e origina uma atmosfera (envolvente) que fomenta a interação e torna imersiva a experiência arquitetónica (Pallasmaa, 2014). A "visão focada" pelo contrário observa simplesmente o externo, a forma arquitetónica.

A compreensão da fenomenologia por parte de Pallasmaa enquanto "olhar puro da essência das coisas", que faz referência à fenomenologia de Husserl, nomeadamente ao olhar sem pressuposições intelectuais, conduziu-o a introduzir a noção de "arquitetura frágil" ou mais precisamente de "de imagem frágil" (Pallasmaa em Shirazi, 2014). Esta refere-se a uma arquitetura que é "contextual, multissensorial e sensível" e que aponta ao impacto emocional, sensorial e real por parte de quem usufrui o espaço, e não a 
um conceito arquitetónico pensado numa idealização daquele espaço. Para nomeá-la conjuga as noções débil ontologia e frágil pensamento do filósofo italiano Gianni Vattino (Pallasmaa, 2000), estas - segundo explica- são ideias para entender o significado duma experiência através dum olhar empático. Pallasmaa, como argumenta Vladimir Stevanovic em Phenomenologies of Architecture (2014), "apela aqui à intuição como fonte de conhecimento predominantemente fenomenológico, a qual encontra-se entre a mente e os sentidos" (p. 100). Neste contexto a palavra frágil deve ser lida como o seu antónimo; tal e como o arquiteto e teórico espanhol Ignasi de Solà-Morales empregala em Arquitectura débil = Weak architecture (1987): "esta é a força da debilidade. Aquilo que a arte e a arquitetura são capazes de produzir precisamente quando não se apresentam agressivas e dominantes, mas tangenciais e débeis" (p. 85).

\section{Confronto dos discursos}

Para facilitar uma melhor compreensão e leitura dos discursos analisados por forma a evidencia-los enquanto antagónicos, complementares e desencadeantes a uma fenomenologia atual é apresentado, nesta parte, um confronto dos mesmos.

Como foi contextualizado na segunda parte deste artigo, o movimento moderno idealizou e realizou uma arquitetura onde predominava a usufruição da visão como sentido dominante: tinha o intuito de internacionalizar-se pela homogeneização da linguagem arquitetónica num estilo arquitetónico desprovisto de ornamento, de muro cortina e de um acentuado carácter da envoltura (que significou também uma omissão do lugar). Na arquitetura, a fenomenologia teceu críticas à construção da imagem do movimento moderno.

Norberg-Schulz, no seu discurso crítico, problematizou sobre a falta de consciência da realidade dos lugares na implementação do estilo internacional. Como resposta, e para enfrentar esta questão, abordou a problemática arquitetura-lugar recuperando 0 antigo conceito genius loci. Este arquiteto evidenciou a consideração da arquitetura como uma imagem de um lugar e de um tempo específicos. Esta imagem, que é visível através da linguagem arquitetónica, tinha a capacidade de traduzir a realidade num entorno construído e encarar significados existenciais. Norberg-Schulz foi construindo o seu discurso a partir dessas imagens para se referir ao sentido do lugar (o genius loci de sítios específicos), que se revela por intermediação da linguagem arquitetónica.

Para ilustrar o seu raciocínio, Norberg-Schulz apresenta imagens fotográficas de encenações arquitetónicas dos lugares que exemplificam o genius loci nas quais se percebe que significam uma fixação das perspetivas representadas. Esta metodologia de trabalho não se separa do paradigma ocular-centrista e responde a uma continuação do mesmo. Note-se que no método de representação por imagem fotográfica a cena é fixada pelo sujeito que a enquadra. Encenação e sujeito encontram na fotografia o mesmo destino de quietude e imobilidade. Na fenomenologia de Norberg-Schulz parece existir uma redução da percepção do sujeito ao sentido da vista. Constrói-se uma realidade por coleção de imagens retinais. Compreende-se assim que a arquitetura enquanto imagem vem ser a premissa sobre a qual Norberg-Schulz constrói o seu discurso.

$7 \quad$ Para Pallasmaa a Villa Mairea de Alvar Alto exemplifica uma "arquitectura frágil" porque reúne e articula multiplex fatores, a saber: "[a arquitectura da Villa Mairea] em lugar de aspirar à pureza conceptual e formal, buscava reconciliar opostos como a natureza e a cultura, a história e a modernidade, a sociedade e 0 individuo, a tradição e a inovação a estandardização e a variedade, 0 universal e o regional, o intelectual e o emocional, o racional e 0 intuitivo" (Pallasmaa em Shirazi, 2014, p. 79).

8 As superfícies e formas são arquitetadas para serem sentidas (toque dos olhos e os demais sentidos).
Embora seja ponto de partida, continua a estar ligado ao paradigma (ainda) dominante da supremacia da visão, o que (de)limita os alcances pretendidos por Norberg-Schulz no seu discurso.

Contrariamente a este argumento de Norberg-Schulz, Pallasmaa afasta-se da referência de imagem para análise da arquitetura e dirige o seu discurso ao corpo do sujeito como integrador das experiências sensoriais (crítica o paradigma da supremacia da visão). Pallasmaa considera o sujeito na sua corporalidade como perceptor do espaço. Neste processo de percepção o corpo inteiro joga com todos os sentidos (não só com a vista ${ }^{8}$ ). Para Pallasmaa, é fundamental o papel de movimento do sujeito no espaço, induzido e conduzido pela essência verbal de tudo o que arquitetura configura e articula para esse desígnio. Pallasmaa é consciente que só por meio do movimento descobrem-se as infinitas variáveis do espaço arquitetónico. Aqui há uma grande diferenciação no que respeita à forma como a arquitetura é assimilada entre os discursos de Norberg-Schulz e Pallasmaa, particularmente, no que concerne à consideração do sujeito (perceptor) 
perante do objeto (arquitetónico); no primeiro o sujeito parece necessitar de corporeidade (esta omnipresente e é quem cria a imagem); no segundo é na corporeidade do sujeito onde, finalmente, define-se o espaço (existe um intercâmbio e permutação em que 0 corpo funde-se com o espaço criando um "espaço corporal"). Neste segundo discurso, a essência verbal da arquitetura predomina sobre linguagem arquitetónica.

Esta presença corporal na arquitetura, e a consideração do corpo enquanto conceito, é o motivo que cria a ponte para uma fenomenologia contemporânea na arquitetura, conhecida por: Nova Fenomenologia. Na Nova Fenomenologia ${ }^{9}(2007) 0$ filósofo Hermann Schmitz desenvolve a noção corpo ${ }^{10}$ de maneira dual. Para isso baseia-se nas palavras Leib e Körper ${ }^{11}$ (relativas ao corpo) para estabelecer uma diferenciação, respectivamente, entre corpo sensível e corpo visível. Leib é entendido como o estrato de sentimentos involuntários e imediatos que o individuo tem e independente das experiências perceptivas ou tácteis na esfera do seu Körper (Schmitz, 2016). Leib, portanto, vem a ser o locus do que nos atinge em primeira instância. Temos como exemplo a expressão de Peter Zumthor: "Entro num edifício, vejo uma habitação, e numa fração de segundos tenho este sentimento sobre o que é" (2006, p. 13), aqui 0 corpo sensível é o que está a ser atingido. Reforçando esta ideia, Zumthor acrescenta: "percebemos atmosfera através da nossa sensibilidade emocional -uma forma de percepção que trabalha incrivelmente rápido... Somos capazes de apreciar de forma imediata, de dar uma resposta emocional espontânea" (Zumthor, 2006, p. 13).

Pallasmaa e Schmitz partilham a ideia de espacialidade enquanto dado primário do que se percebe/sente na própria corporalidade. Esta associação espaço-corpo significou uma ponte à introdução da Nova Fenomenologia. Nesta, há consciência do corpo sensível raciocínio que, finalmente, possibilita perceber-se atmosfera como qualidade arquitetónica. Pallasmaa já tinha afirmado que os inúmeros fatores de complexa fusão multissensorial que determinam a qualidade de um espaço são "imediatamente e sistematicamente captados como atmosfera, sentimento, modo ou ambiência" (Pallasmaa en Havik, Teerds \& Tielens, 2013, p. 5). Aqui, atmosfera, distingue-se intercedendo conceptualmente entre a esfera da presença percetível da própria arquitetura (articulação e idade dos materiais, proporção do espaço, ritmos, luz, vínculos com lugar e com outros edifícios, etc.) e a resposta emocional dessa presença no sujeito. O teórico alemão Gernot Böhme na Nova Estética de Atmosfera ${ }^{12}$ (1995) define atmosfera como "uma sínteses entre a realidade comum do percebido e do perceptor" (Böhme, 1993, p. 122); o que quer dizer que atmosfera é gerada (cria-se) na/da "sínteses" da "força da presença" da arquitetura com/no corpo sensível, ou em outras palavras: da/na dialética de integração entre o que arquitetura "emana" e os sentimentos imediatos (em nós) originados dessa emanação arquitetónica. Neste contexto existe um evidente sentir empático com a arquitetura, referido por Pallasmaa, na revelação relativa ao intercâmbio e permutação em que o corpo funde-se com 0 espaço na experiência arquitetónica existencial.

$9 \quad$ nome Nova Fenomenologia segundo Gernot Böhme foi utilizado por Hermann Schmitz para distinguir a sua fenomenologia das versões clássicas, nomeadamente as de Husserl, Heidegger e Merleau-Ponty (Böhme, 2014).

$10 \quad$ Na Nova Fenomenologia o conceito do corpo é mais desenvolvido do que na fenomenologia clássica (especificamente de Merleau-Ponty) (Blume, 2010).

11 Termos em alemão para noções que já tinham sido abordadas por Husserl mas com marcadas diferenças.

12 A Nova Estética de Atmosfera substitui o desinteresse contemplativo da estética tradicional pelo conteúdo perceptual ativo; e a noção de estética recobra o seu sentido original de aisthētik $\llbracket$ como una teoría (geral) da perceção que considera o impacto afectivo do observado. o impacto afectivo do observado.

\section{Conclusões}

Percebe-se que o interior e o exterior na arquitetura são domínios interdependentes. As fenomenologias "do interior" e "do exterior" surgiram, não porque os domínios se entendam independentes, senão pela necessidade de enfatizar sobre problemas que foram surgindo a partir da difusão e concretização do estilo internacional, nomeadamente a homogeneização da arquitetura, a perda da relação com lugar e com o corpo. Inicialmente Norberg-Schulz problematizou sobre a relação (conexão) arquitetura-lugar apresentando uma fenomenologia focada no exterior (na linguagem $\mathrm{e}$ encenação arquitetónica) e numa segunda abordagem fenomenológica da arquiteturaPallasmaa problematizou sobre a supremacia da visão na cultura ocidental propondo uma "fenomenologia de dentro", uma "fenomenologia da proximidade" analisando a relação arquitetura-corpo.

Norberg-Schulz apresenta uma "fenomenologia do exterior" focalizada na arquitetura enquanto imagem com uma aparente ausência da corporalidade no sujeito. A forma como é apresentada deixa um vazio que é completado por uma a "fenomenologia do 
interior" que Pallasmaa propõe. Nesta fenomenologia, permite-se "abrir a porta" ao usufruidor para o interior do espaço, onde o corpo do sujeito (e não apenas do objeto arquitetónico) está presente; experimentando-se a arquitetura de maneira autêntica, integral e articulada enquanto experiencia "vivida" e não apenas "vista" e ou "observada".

As limitações evidenciadas no discurso de Norberg-Schulz, veio limitar o alcance da sua fenomenologia que está praticamente restrita ao exterior, separando-se do sentido Heideggereano (no qual se baseou). Pallasmaa, por o seu lado, apresenta também um descuido teórico no que respeita à problemática circundante do edifício em favor da experiência do corpo no espaço (arquitetónico). Nesta ordem, o primeiro discurso tem conotações "macro" (pela preocupação na encenação da arquitetura) 0 segundo em contraposição, parece estar mais ligado ao âmbito dos "detalhes" que a arquitetura configura para o corpo. Contudo, e independentemente das ausências nos discursos teóricos que cada um apresenta, o contributo da análise da fenomenologia da arquitetura pelo ponto de vista de Norberg-Schulz e Pallasmaa demonstra que das suas visões consegue-se construir a associação corpo-espaço-lugar, essencial para introduzirmos e percebermos uma fenomenologia de arquitetura mais sensível e oportuna às exigências do sujeito na contemporaneidade.

Nesta sequência de pensamentos, tem-se evidenciado o passo de uma fenomenologia onde o sujeito parece necessitar de corporeidade a uma onde o sujeito existe numa presença corporal. Na fenomenologia de presença corporal a experiência do sujeito móvel - perceptual e cognitivamente alerta- revela na arquitetura integridade pelas suas: essência material, corpórea e emocional; esta ultima, pertencente à esfera dos sentimentos, que nos introduz à Nova Fenomenologia.

Na Nova Fenomenologia de Schmitz revela-se a dimensão dos sentimentos na corporalidade, fundamental para a perceção de atmosfera na arquitetura. Schmitz desenvolve o conceito do corpo sensível significando a abertura a esta fenomenologia. Nesta posição, o corpo sensível, tem sentimentos involuntários e imediatos que são teoricamente independentes das experiências percetivas e que (no entanto) possibilitam perceção de atmosfera. Com o corpo sensível percebe-se esta qualidade na arquitetura ao mostrar o impacto emocional, sensorial e real por parte de quem usufrui os espaços interiores e exteriores, fazendo isto a ligação à ideia de arquitetura frágil de Pallasmaa. $\mathrm{Na}$ fenomenologia de arquitetura, atmosfera nasce e define-se, resumidamente, no encontro e junção da realidade do sujeito perceptor e da obra percebida.

Conclui-se que: os discursos de Norberg-Schulz e Pallasmaa são fundamentais dentro do movimento fenomenológico de arquitetura por terem investigado relações da presença do sujeito nos domínios arquitetónicos, exterior e interior. Estes discursos, para além de essenciais na autêntica experiência arquitetónica, elucidaram uma direção efetiva a uma fenomenologia integral e apropriada à teoria e prática arquitetónica contemporânea. A fenomenologia de atmosfera, cria um contexto de idealização e experimentação para a geração de atmosferas na arquitetura. O fundamental que reside neste artigo é de perceber (cronologicamente) essa sequência de pensamentos dos arquitetos-fenomenólogos e dos teóricos referidos como desencadeantes para uma fenomenologia contemporânea da arquitetura; da qual são atuais praticantes arquitetos proeminentes, como Daniel Libeskind, Steven Holl e Peter Zumthor.

\section{Referencias bibliográficas}

Amorim, P. (2013). Fenomenologia do espaço arquitetónico. Projecto de requalificação do Museu Nogueira da Silva (Dissertação de mestrado, Universidade da Beira Interior UBI). Disponível em: https://ubibliorum.ubi.pt/handle/10400.6/1925. Acesso em: 21 junho, 2018.

de Solà-Morales, I. (1987). "Arquitectura débil". Quaderns d'arquitectura i urbanisme, (175), 72-85. Disponível em: http://www.raco.cat/index.php/ QuadernsArquitecturaUrbanisme/article/view/202344/299099. Acesso: 5 janeiro, 2018.

Führ, E. (1998). "genius loci” Phänomen oder Phantom?. Wolkenkuckucksheim, 3(2). 
Disponível em: http://www.cloud-cuckoo.net/openarchive/wolke/deu/Themen/982/ Fuehr/fuehr_t.html. Acesso: 25 janeiro, 2018.

Blume, A. (2010). Hermann Schmitz (1928-). En H. R. Sepp, \& L. Embree (Eds.), Handbook of Phenomenological Aesthetics, Contributions To Phenomenology, 59, 307-309. doi: 10.1007/978-90-481-2471-8_61

Böhme, G. (1993). "Atmosphere as the Fundamental Concept of a New Aesthetics". MIT Massachusetts Institute of Technology. Thesis Eleven, 36 (1), 113-126. doi: 10.1177/072551369303600107

Böhme, G. (2014). The theory of atmospheres and its applications. INTERSTICES, 15, 92-99. Disponivel em: http://interstices.aut.ac.nz/ijara/index.php/ijara/article/ view/201. Acceso: 12 março, 2018.

Havik K., Teerds H., Tielens G. (2013). "Editorial. Building Atmosphere". Journal of Architecture, OASE, 91, 3-12. Disponível em: http://www.oasejournal.nl/en/ Issues/91/Editorial\#003. Acesso: 03 março, 2018.

Heidegger, M. (1993) [1951]. Building, Dwelling, Thinking. Em: D. Farrell (Ed.), Martin Heidegger. Basic Writings (p. 362). London: Routledge.

Holl, S. (1996). Intertwining. New York: Princeton Architectural Press. Disponível em: http://www.geometree.net/ukans/readings/intertwining-reading.pdf. Acesso: 15 janeiro, 2018.

Norberg-Schulz, C. (1980). Genius Loci: Towards a Phenomenology of Architecture. London: Academy Editions.

Norberg-Schulz, C. (1979). Kahn, Heidegger and the Language of Architecture. Oppositions, 18, pp. 29-47.

Norberg-Schulz, C. (1996). Nightlands, Cambridge, London: MIT Press. Pallasmaa, J. (2000). "Hapticity and Time: Notes on fragile architecture". Architectural Review, (May), 78-84.

Pallasmaa, J. (2006). Los ojos de la piel: la arquitectura y los sentidos. Barcelona: Editorial Gustavo Gili, SL.

Pallasmaa, J. (2014). "Space, Place and Atmosphere. Emotion and Peripheral Perception in Architectural Experience", Lebenswelt, 4.1, 230-245. Disponível em: http://riviste.unimi.it/index.php/Lebenswelt/article/view/4202/4292. Acesso: 13 janeiro, 2018.

Pallasmaa, J. (1996). The Geometry of Feeling: a look at the phenomenology of architecture. in K. Nesbitt (ed.), Theorizing a New Agenda for Architecture, An Anthology of Architectural Theory.New York, pp. 447-453.

Schmitz, H. (2016) "Atmospheric Spaces", Ambiances Redécouvertes. doi : 10.4000/ ambiances.711.

Shirazi, M. R. (2014). Towards an Articulated Phenomenological Interpretation of Architecture: Phenomenal Phenomenology. Oxfordshire e New York: Routledge Research in Architecture.

Stevanovic, V. (2014). Phenomenologies of Architecture. SAJ Serbian Architectural Journal, 6, 89-106. Disponível em: http://saj.rs/wp-content/uploads/2016/11/SAJ2014-01-V-Stevanovic.pdf. Acesso: 6 dezembro, 2017.

Zumthor, P. (2006). Atmósferas. Barcelona: Editorial Gustavo Gili, SL. 